\title{
An imaging-in-flow system for automated analysis of marine microplankton
}

\author{
Christian K. Sieracki*, Michael E. Sieracki, Charles S. Yentsch \\ Bigelow Laboratory for Ocean Sciences, PO Box 475 McKown Point, West Boothbay Harbor, Maine 04575, USA
}

\begin{abstract}
Present automated systems for counting and measuring marine plankton include flow cytometers and in situ plankton video recorders. Neither of these approaches are optimal for the microplankton cells which range in size from 20 to $200 \mu \mathrm{m}$ and can be fewer than $10^{4} \mathrm{l}^{-1}$. We describe here an instrument designed for rapid counting, imaging and measuring of individual cells and particles in the microplankton size range from cultures and natural populations. It uses a unique optical element to extend the depth of focus of the imaging lens, allowing a sample stream flow rate of $1 \mathrm{ml} \mathrm{min}^{-1}$. The instrument stores a digital image of each particle along with real time fluorescence and size measurements. An interactive cytogram links a dot-plot of the size and fluorescence data to the stored cell images, allowing rapid characterization of populations. We have tested the system on live phytoplankton cultures and bead standards, proving the system counting and sizing accuracy and precision. The system provides images and size distributions for cultures or natural marine samples. It has been used successfully at sea to continuously monitor particles while underway. It may prove useful in studies of plankton community structure, ocean optics and monitoring for harmful algal species.
\end{abstract}

KEY WORDS: Imaging · Flow cytometer Microplankton - Binary optical element Cell counting $\cdot$ Cell sizing - Natural populations · High rate $\cdot$ Cultures

\section{INTRODUCTION}

The distributions and size spectra of particles in marine water influence the inherent optical properties and reflect plankton community structure. The majority of particles in surface waters are planktonic organisms, including bacteria, protists, and metazoans. Nonliving, detrital particles are abundant in coastal waters, in the deep ocean, and in surface water, following phytoplankton blooms. Traditionally, optical microscopes have been used to identify and count marine particles. Since sample preparation and analysis by traditional methods is time-consuming, applications that require size and abundance information, but can sacrifice taxonomic detail, are better handled by automated systems. A variety of instruments have been developed or used for automated analysis of natural particle populations by detecting, counting and measuring individual particles and planktonic organisms at high rates. Since particles in natural waters decrease in

•E-mail: csieracki@bigelow.org abundance as a power of size (McCave 1984), automated systems tend to be optimal for restricted size ranges of the whole spectrum.

Early studies used the Coulter principle (Coulter $1957)$ to rapidly obtain marine particle size distributions both in situ (Maddux \& Kanwisher 1965) and in discrete water samples (Sheldon et al 1972). These studies provided the basic knowledge of particle size spectra geographically across ocean basins and vertically with depth. This technique could not be used to identify particle types and did not provide any information on optical properties of the particles present.

More recently, instruments capable of measuring the optical properties of marine particles have been used. Present optical 'plankton counters' determine particle size by measuring particle light scatter (Yentsch \& Yentsch 1984, Freimann 1996). These instruments provide detailed profiles of size with depth. However, particle identification must be accomplished with separately obtained samples.

Flow cytometers measure particle light scatter and fluorescence at different wavelengths (Yentsch et al. 
1983, Chisholm et al. 1986, Yentsch \& Spinrad 1987. Phinney \& Cucci 1989) They are optimal for particles ranging from about 0.5 to $20 \mu \mathrm{m}$ in diameter which exist at concentrations between $10^{6}$ and $10^{9} \mathrm{l}^{-1}$ (Olson et al. 1991). Fluorescence is used to identify particles containing chlorophyll-primarily phytoplankton. Specialized flow cytometers have been built to handle larger particles but their use is not widespread (Dubelaar et al. 1989, Peeters et al. 1989). In all cases flow cytometers are able to measure a few optical parameters from each particle very rapidly, but identification of particles from a complex mixture, such as that found in natural waters, is limited.

The imaging of particles in flow has evolved in parallel with techniques for measuring optical properties. Early imaging of particles in flow was accomplished with photographic film and electronic or computer control of imaging and flash (Kachel et al. 1979, Kay et al. 1979). As high performance computers and means of capturing digital images developed, systems were designed to image, analyze and count marine particles (Hüller et al. 1994) electronically.

A module for the EurOPA flow cytometer has been designed to image particles in flow when the instrument receives a fluorescence trigger signal (Dubelaar et al. 1994, Wietzorrek et al. 1994). Particles imaged by this system have the size range of 3 to $50 \mu \mathrm{m}$. While this instrument can image these particles, it is limited by the flow cytometer hydraulic sheath hardware and its flow rate limit of $50 \mu \mathrm{ll}^{-1}$. It is also not suited to handling particles larger than $100 \mu \mathrm{m}$ due to the sheath nozzle size.

The current macro flow planktometer (Hüller et al. 1994) provicles images of particles from 100 to $2000 \mu \mathrm{m}$ in discrete samples. Particle volume by electrical resistance, and fluorescence is measured for each particle and a subset of the particles is imaged. This system has proven useful in the analysis of copepods and larger detrital particles.

The video plankton recorder (VPR) (Davis et al. 1992, Gallager et at. 1996) also provides images of in situ marine particles. Its use has provided extensive information on plankton, including microaggregation data and detailed 2D profiles (tow-yos) of plankton distributions relative to hydrographic features. It has been used to image countless individual plankters with a resolution that allows determination of animal orientation and taxonomic identification. This system is limited to imaging particles larger than approximately $200 \mu \mathrm{m}$.

These instruments leave a significant region of the microplankton size/abundance space largely unaddressed by automated approaches. This size range, 20 to $200 \mu \mathrm{m}$ (Sieburth et al. 1978), includes the phytoplankton which dominate during bloom conditions, including larger diatoms, dinoflagellates and potentially harmful algae. Microzooplankton also fall in this size range and exist in natural waters at concentrations between 10 and $10^{5} \mathrm{l}^{-1}$. We describe here an automated system, the Bigelow flow cytometer and microscope (Flow CAM), specifically designed for rapidly analyzing discrete and pumped natural samples and cultures containing particles in the microplankton size range.

\section{MATERIALS AND METHODS}

Instrumentation. The systems diagram (Fig 1) shows the instrument configuration and the general flow of the sample and signals. The sample is drawn into the Flow CAM flow chamber where it is monitored for particles. All particles in this flow are kept in focus by a custom depth of focus enhancing optical element which prevents blurring and assures proper particle counting and sizing Particles are counted by imaging the flow with the video camera/framegrabber either at preset intervals or when fluorescent particles pass through the field of view. The resulting digitized images and other information are then displayed, analyzed and stored by the computer. After an experiment, this data may be reviewed with the Flow CAM software user-interactive menus.

Flow. A peristaltic pump on the downstream side of the flow chamber was used to draw the sample through the instrument (Fig. 1A). The thickness of flow in this chamber generally matches the depth of focus of the imaging optics. Fluorescence triggered counts of particles are conducted with a custom $1 \mathrm{~mm}$ square chamber. High density cultures were counted with a $3.0 \mathrm{~mm}$ wide by $0.3 \mathrm{~mm}$ thick chamber (VitroCom Inc., Mountain Lakes, NJ, USA).

Optics. A 0.12 numerical aperture $4 \times, 170 \mathrm{~mm}$ tubelength Leitz objective is used to image the flow onto a video camera, focus fluorescence excitation onto the chamber and focus the fluorescence emission onto a $1 \mathrm{~mm}$ slit in front of a photomultiplier tube (PMT) (Fig. 1B). A filter set (XF18, Omega Optical, Brattleboro, VT, USA) is used with a $200 \mathrm{~W}$ mercury arc Koehler illuminator for fluorescence measurements. This filter set has a fluorescence excitation range of 435 to $470 \mathrm{~nm}$ and an emission range of 520 to $700 \mathrm{~nm}$. Fluorescence emissions are focussed onto the slit/ photomultiplier which is parfocal with the video camera. The slit has the effect of reducing background noise and increasing the system's ability to detect passing fluorescent particles

A custom depth of focus enhancing optical element is used with the objective to increase the system depth of focus without reducing the lateral resolution. This optical element consists of a sheet of soda lime glass which is etched to one of 4 depths in a specific pattern of concentric rings. This introduces controlled spheri- 
cal aberration to the objective and changes the focus to a continuum of foci $300 \mu \mathrm{m}$ long. This element was fabricated based on the unoptimized 4 -level aberration corrector described in chapter 3 of the PhD thesis of $\mathrm{C}$. Sieracki (Sieracki 1995). We have found that its depth of focus enhancing properties are useful in this application. In the Flow CAM, the element is $5 \mathrm{~cm}$ behind the threads of the objective for best operation. The performance of the element is characterized below.

Electronics. The Flow CAM is operated in 2 different modes, dependent on the concentration of cells in the sample. In fluorescence triggered mode, a photomultiplier tube (RCA \# R-136) converts fluorescence to a signal current that is processed by the detection electronics. These electronics generate a trigger signal when the fluorescence signal is greater than a manually set threshold. For best imaging, the circuitry generates the trigger signal at the next video camera vertical synchronization pulse after the threshold is exceeded. The Flow CAM computer measures the particle fluorescence continuously at $100 \mathrm{kHz}$ via an analog to digital converter (LTC 1273 Linear Technology, Milpitas, CA, USA) and interface board (PDS-611, JDR Microdevices, San Jose, CA). The $100 \mathrm{kHz}$ sample rate provides 2 samples $\mu \mathrm{m}^{-1}$ of particle size at a flow rate of $1 \mathrm{ml} \mathrm{min}-1$ when a $1 \mathrm{~mm}$ slit is placed in front of the photomultiplier tube. Fluorescence is measured before, during and after fluorescence events to determine the peak fluorescence of each triggering particle. When a trigger is detected by a separate threshold circuit, the computer finds the peak by scanning the digitized fluorescence waveform up to the time of the trigger signal. In auto-trigger mode, the Flow CAM electronics are configured to automatically trigger several times every second synchronized with the video camera vertical signal. No fluorescence is measured in this mode. When the trigger occurs, the electronics illuminate a high intensity $670 \mathrm{~nm}$ light emitting diode (LED) below the flow chamber and paraxial with the imaging optics. The LED (276-086, Radio Shack, Fort Worth, TX, USA) is driven at $12 \mathrm{~V}$ for $200 \mu$ s to capture an instantaneous image of the particles in the flow chamber on the video camera. While this voltage is beyond the limits of continuous LED operation, it is within safe limits of pulsed operation (Hüller et al. 1994). The trigger signal also triggers the framegrabber (DT3152, Data Translation, Marlboro, MA, USA) to digitize the video image. The video is from either a nuvicon (NC-67M, Dage-MTI, Michigan City, IN, USA) (Gamma $=1.0$ ) or CCD camera (KP-M/2 Hitachi) (Gamma $=1.0$ ).

Software-data acquisition and presentation. When the computer detects a trigger, an image is digitized by the framegrabber and a sub-image of each detected particle is extracted. The software qualifies pixels by scanning the image for pixels which are different from
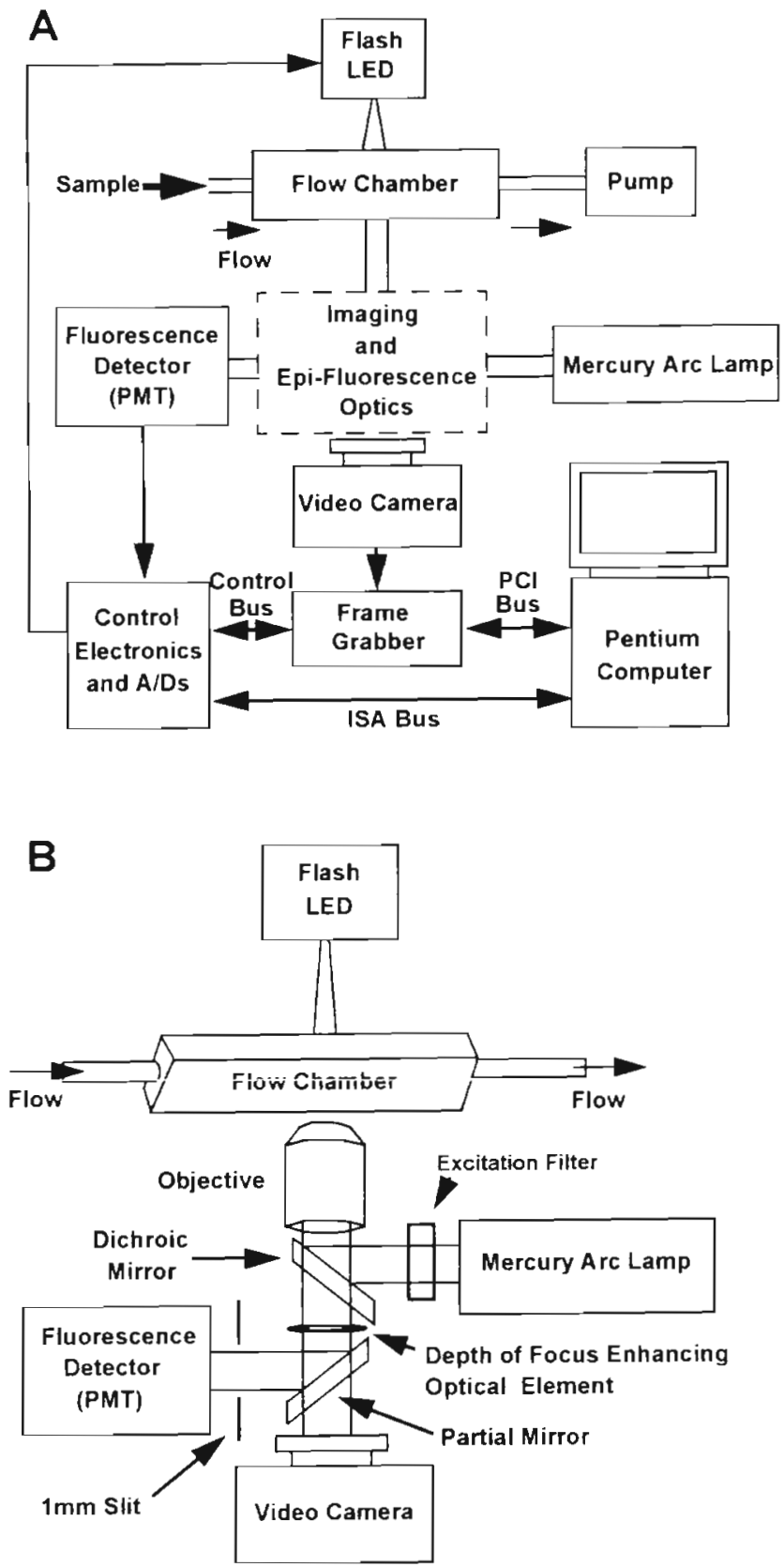

Fig. 1. Block diagram of the Bigelow flow cytometer and microscope (Flow CAM) showing (A) the major components and $(B)$ the epi-fluorescence and imaging optics. The sample is drawn into the flow chamber where it is illuminated with Hg arc lamp excitation. When a fluorescing particle passes the imaged area of the chamber, the photomultiplier tube (PMT) signal triggers the framegrabber and light-emitting diode (LED), capturing a transmitted light image on the computer

their immediate neighbors and distant neighbors $(20$ pixels away) by a user-selected brightness value Qualified pixels within a pre-determined distance of each other are grouped to form images of particles. 
The area of each particle is computed by summing the number of qualified pixels in each particle image and multiplying the result by the equivalent physical area of a pixel. When operating in fluorescence triggered mode, the software also reads the fluorescence waveform and measures the peak fluorescence. The particle area, fluorescence, time of passage, and location in the flow image is stored in an ASCII-formatted file. The sub-images of individual particles are saved in a collage file. Several of these collage files may be generated for each Flow CAM experiment. A separate list file is generated to link these sub-images with the particle size and fluorescence data.

When a sample is running on the Flow CAM, an image is analyzed in 0.5 to $1.0 \mathrm{~s}$ depending on the number of particles in the image. The electronics can handle up to 60 triggers $\mathrm{s}^{-1}$, meaning that the image analysis is the most significant bottleneck. The maximum system rate is therefore approximately 2 fluorescent particle events $\mathrm{s}^{-1}$, or 1 densely populated culture image $s^{-1}$ with up to 300 particles per image.

After an experiment, Flow CAM data may be reviewed in 2 modes: (1) image collage or (2) interactive scattergram. In image collage mode, the user may review a series of collage files using the computer mouse. This allows the user to examine particle morphology and visually classify particle types. In interactive scattergram mode, data is presented to the user as a fluorescence versus size dot-plot, analogous to a flow cytometer 'cytogram.' If the user selects a region of the scattergram with the computer mouse, images of particles in that region are displayed on the computer screen. This allows the user to examine images from populations with distinctive size and fluorescence properties.

The user may also review the ASCII-formatted data with commercial spreadsheet programs. This allows the user to readily generate cell counts and fluorescence and size histograms for each sample. This data also contains the location of each particle in the original image which is used to remove redundant data from particles that may have become attached to the flow chamber.

Depth of focus enhancement. A test slide was prepared by drying $2.23 \mu \mathrm{m}$ fluorescent latex beads (Polysciences, Inc., Warrington, PA, USA) onto a microscope slide. We then took successive images of a region of the slide with the Flow CAM objective, changing the focus by $25 \mu \mathrm{m}$ between each image. The grey-level intensity value at the center of the same bead in each image was measured with a graphics program at each focus setting to construct the axial intensity point spread function. Beads were imaged with and without the custom optical element for comparison. We used the nuvicon camera for this experiment and the CCD camera for all others.
We conducted additional tests to measure the potential blurring (i.e. enlarging) of particles in the flow stream above or below the position of optimal focus. Three different specimens were placed on a microscope slide under a coverslip: a $35 \mu \mathrm{m}$ diameter latex bead and cells of Ceratium sp. and Alexandrium tamarense (CCMP115). For each focus setting, each single bead or cell was imaged and measured 10 times by the Flow CAM. This was repeated at $50 \mu \mathrm{m}$ increments over a range of optimal focus $\pm 500 \mu \mathrm{m}$, with and without the BOE in place.

Calibration of flow CAM sizing and counting. A variety of cell types and bead sizes was used to test the system's particle sizing and counting accuracy. Cultures chosen for this study were Alexandrium tamarense (CCMP115), Biddulphia sp. (CCMP147), Cyclotella meneghiniana (CCMP337), Gambierdiscus toxicus (CCMP1733), Nitzschia ovalis (CCMP1118) and NaviCula sp. (CCMP1703), obtained from the Provasoli-Guillard National Center for Culture of Marine Phytoplankton (CCMP) in West Boothbay Harbor, Maine, USA. A mixture of 15, 30, 41 and $61 \mu$ m latex beads (Coulter Corporation, Miami, FL, USA) was also used for sizing calibration

Sparse, fluorescent cells were counted with the system in fluorescence triggering mode with a maximum trigger rate of about 1 event $\mathrm{s}^{-1}$, or 60 cells $\mathrm{ml}^{-1}$ at a flow rate of $1 \mathrm{ml} \mathrm{min}{ }^{-1}$ To compensate for this slow trigger rate, dense cultures were diluted with seawater to a density lower than 50 cells $\mathrm{ml}^{-1}$. The height at which the particles appeared inside the $1 \mathrm{~mm}$ square chamber was sufficiently restricted by laminar flow to provide proper focussing. The pump exhaust was collected during counts and the volume was measured to determine the volume analyzed. At the end of the experiment, the total number of cells detected was divided by the volume analyzed and multiplied by the dilution factor to determine cell concentration $\left(\mathrm{ml}^{-1}\right)$.

For bead mixtures or denser cell cultures, the sample was treated differently. Cultures were diluted to a density of fewer than $10^{6}$ cells $\mathrm{ml}^{-1}$ if they were above this limit. Cells were then counted by drawing the sample through the $3.0 \mathrm{~mm}$ wide $\times 0.3 \mathrm{~mm}$ thick flow chamber and periodically triggering the Flow CAM. The system counted and analyzed separate cells in a $1 \times 1 \mathrm{~mm}$ field of view, a subsample of the $3 \mathrm{~mm}$ wide flow. In autotrigger mode, the flow sample stream is regularly sampled by the imaging system - not every cell is measured and no fluorescence measurement is taken. From the 1000 cells analyzed for each experiment, we computed the average number of cells observed per image $(0.3 \mu \mathrm{l})$. This was multiplied by the Flow CAM calibration factor for the flow chamber $\left(3500 \mathrm{ml}^{-1}\right)$ and by the dilution factor to determine the concentration of cells in the original sample. In the case of the chain- 
forming Biddulphia sp., we measured the area of a single cell and then computed the number of cells in each chain by dividing the total observed chain area by the area of a single cell. To compute the statistics for the individual bead types in the mixture, standard deviations were computed on the data within $\pm 7 \mu \mathrm{m}$ of the peak.

Each culture was sized and counted using traditional visual methods. A Zeiss microscope with a calibrated ocular micrometer was used to measure the size of 10 or more live cells of each culture. Motile forms were measured when cells were temporarily stationary. Each sample was preserved with Lugol's solution and counted visually using a $0.1 \mathrm{ml}$ Palmer-Maloney chamber unless the cell density was below several thousand $\mathrm{ml}^{-1}$, in which case a $1 \mathrm{ml}$ Sedgewick-Rafter chamber was used. To assure statistical significance, we counted at least several hundred of each cell type using both the Flow CAM and manual methods (Venrick 1978). We counted cultures of each cell type both ways once a day for $6 \mathrm{~d}$ as they progressed through different growth phases. Some of the cultures expired before the sixth day, resulting in a total of 28 valid cell counts. For chain forming cultures, single cells were counted independent of chain length.

System counting precision was tested in another set of experiments. We used cultures of Chaetoceros neogracile (CCMP 1318), C. simplex (CCMP 200), Ditylum brightwellii (CCMP 358), Dunaliella cf. tertiolecta (CCMP 1302) and Skeletonema costatum (CCMP 1332). Four replicate Flow CAM counts of 1000 cells and 4 manual counts of 200 cells were performed for each sample. Four replicate counts of 1000 cells were also conducted on a $100,80,60,40,20 \%$ dilution series of $D$. cf. tertiolecta and $5 \mu \mathrm{m}$ beads. Variations were computed from results for manual and Flow CAM count results. For the dilution experiments, we computed the theoretical coefficient of variation as (Venrick 1978) for the practical counts of 200 and 500 .

Measurements of natural assemblages. The Flow CAM was used to measure marine particles in natural assemblages off the shore of Fort Jefferson, Florida (USA) and from Boothbay Harbor, Maine (USA). Water was sampled by a Niskin bottle at $1 \mathrm{~m}$ below the surface and analyzed with the Flow CAM in fluorescence triggered mode.

Continuous, underway sampling was tested along a transect in the Gulf of Maine with the Flow CAM connected to the vessel underway water supply. With the system in fluorescence triggered mode, particles in the water were monitored for several hours at a time, revealing changes in cell size distributions with location. Due to the failure of our temperature sensor, we obtained AVHRR sea surface temperatures for the Gulf of Maine from the nearest clear period, an evening $8 \mathrm{~d}$ after the cruise.

\section{RESULTS}

\section{Depth of focus enhancement}

Fig. 2 compares the measured axial intensity profile of a $2.23 \mu \mathrm{m}$ fluorescent microsphere with and without the depth of focus enhancement element in the optical path. The depth of focus (full width at half maximum) without this element is approximately $75 \mu \mathrm{m}$. With the Flow CAM $1 \times 1 \mathrm{~mm}$ field of view, the clearly imaged volume is $0.075 \mu$ l. With the optical element, the depth of focus is extended to about $300 \mu \mathrm{m}$, indicating a 4 fold increase in the clearly imaged volume $(0.300 \mu \mathrm{l}$ per image).

The optical element improves the particle sizing accuracy over a nearly $\pm 500 \mathrm{~mm}$ focal range within the flow (Fig. 3). Without the element, a $35 \mu \mathrm{m}$ bead and the cells of Alexandrium tamarense and Ceratium sp. showed a measured size variation of 20,32 and $25 \%$, respectively, over a range of optimal focus $\pm 300 \mu \mathrm{m}$. With the element in place, the maximum variations were 3,3 and $5 \%$, respectively. The variation in apparent size was significantly reduced with the element in place.

\section{Particle counting}

Fig. 4 shows 28 cell counts measured with the Flow CAM and manually. The Flow CAM count per unit volume was always within $25 \%$ of the manual count. The highest count difference was encountered with chainforming Biddulphia sp. The next highest error was that associated with counting a senescent culture of $\mathrm{Nitz}$ schia ovalis. Overall, the performance of the system was good over 4 decades $\left(R^{2}=0.976\right)$. The Flow CAM counts of dense cultures were completed in $10 \mathrm{~s}$ for 1000 cells, compared to the $15 \mathrm{~min}$ or longer required for manual counts

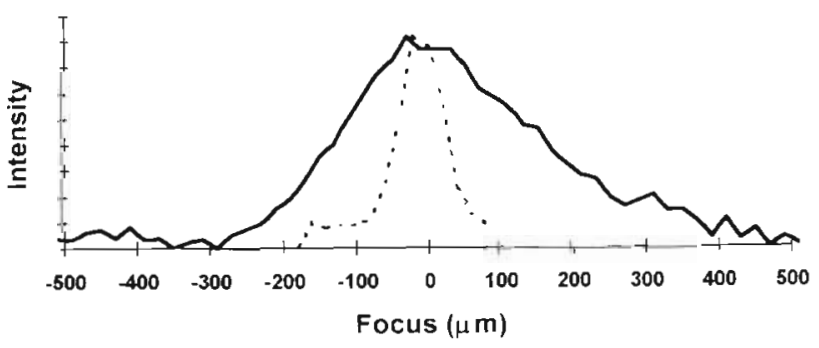

Fig. 2. Axial intensity profile of a $2.23 \mu \mathrm{m}$ fluorescing bead measured with (-) and without (- - the depth of focus enhancing optical element. These profiles show observed intensities as the focus is adjusted from $500 \mu \mathrm{m}$ below to $500 \mu \mathrm{m}$ above the bead. Without the optical element, the depth of focus is approximately $75 \mu \mathrm{m}$. The optical element increases the depth of focus to approximately $325 \mu \mathrm{m}$ 


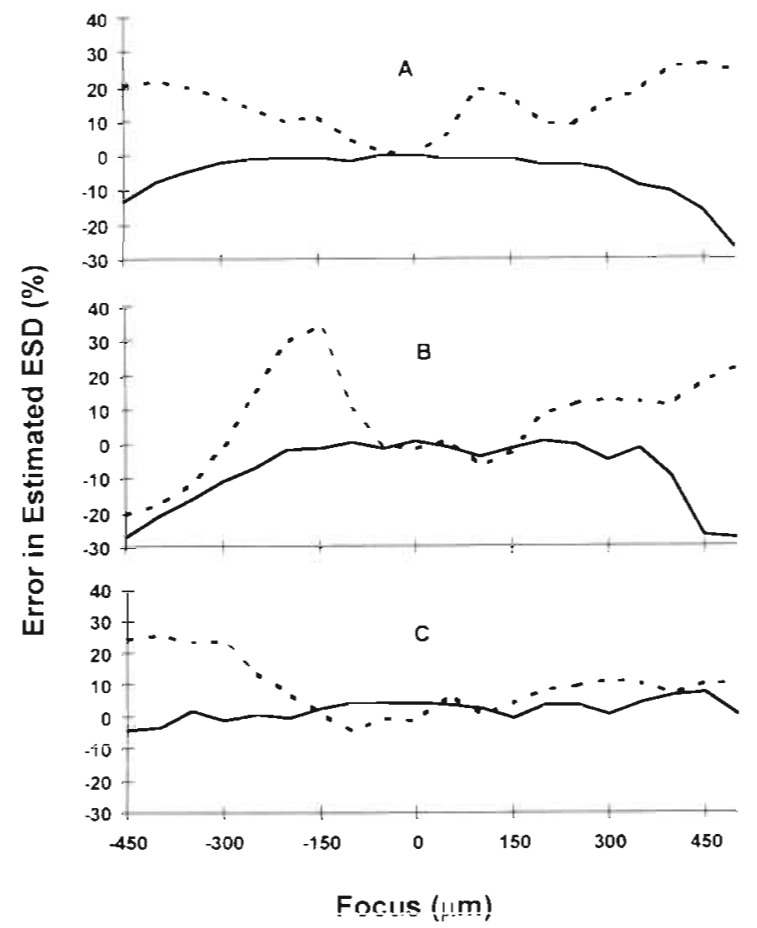

Fig. 3. Effect of focus on the system measurement in equivalent spherical diameter (ESD) of different specimens with (-) and without (-- -$)$ the depth of focus enhancing optical element. (A) $35 \mu \mathrm{m}$ bead, (B) Alexandrium tamarense, (C) Ceratium sp. Error is calculated as percent deviation from the size measured without the optical element with the object in focus. In the absence of the optical element, the apparent size of the particles increases as the focus deviates from the optimum and the image becomes blurred

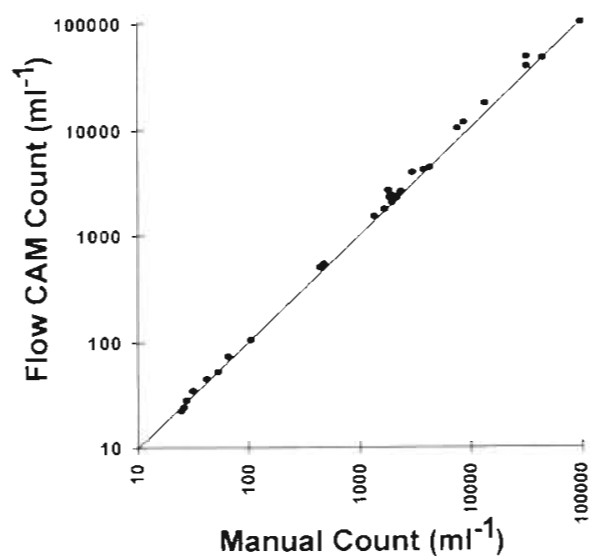

Fig. 4. A comparison of 28 Flow CAM and manual cell counts from 6 different phytoplankton cultures as they progressed along their growth curves. The cell densities ranged from 25 to 100000 cells $\mathrm{ml}^{-1}$. Solid line shows the $1: 1$ line $\left(r^{2}=0.976\right)$

The relationship is linear over the entire range (overall slope $=1.04$ ). The largest discrepancy occurred at the smallest sizes where the Flow CAM increasingly underestimated size as actual size decreased.

The size distributions measured for the bead mixture shows 4 sharply defined peaks (Fig. 7) and the statistics (Table 1) verify the nominal bead sizes and confirm the system sizing accuracy and precision. All of the peaks are narrow, with a small standard deviation. Counts to the right of the $61 \mathrm{~mm}$ bead peak were generated by doublets of $61 \mathrm{~mm}$ beads.
The Flow CAM counts were generally as precise as or more precise than actual and theoretical manual counts due to the larger number of cells counted by machine in each experiment (Fig. 5). The largest counting variations occurred with Chaetoceros neogracile (Expt 1) and Ditylum brightwellii (Expt 5). D. brightwellii generated a slightly larger Flow CAM variation than manual variation. Counts of Dunaliella cf. tertiolecta (Expts 2 \& 11-15) exhibited variation slightly higher than the theoretical values

\section{Particle sizing}

The Flow CAM versus manual size data (Fig. 6) shows strong agreement between the 2 methods $\left(R^{2}=0.996\right)$.

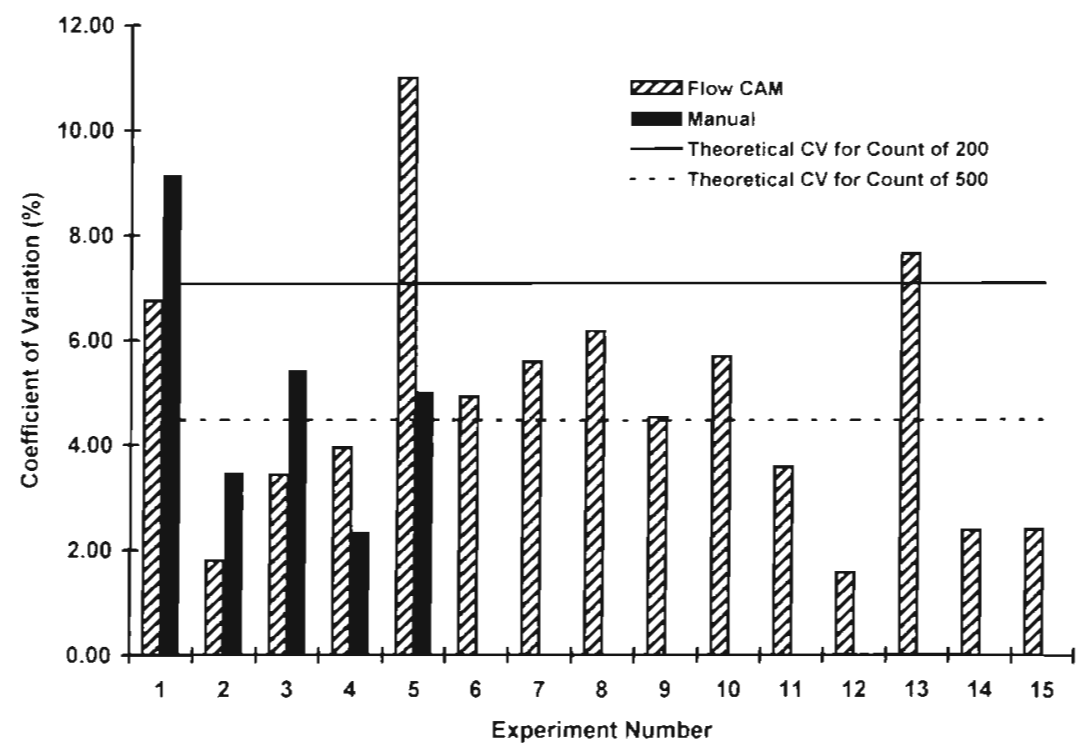

Fig. 5. Precision test results of Flow CAM vs manual counts for (1) Chaetoceros neogracile, (2) Dunaliella cf. tertiolecta, (3) Skeletonema costatum, (4) Chaetoceros simplex, (5) Ditylum brightwellii, $(6-10)$ dilutions of $5 \mu \mathrm{m}$ beads and (11-15) dilutions of Dunaliella cf. tertiolecta 


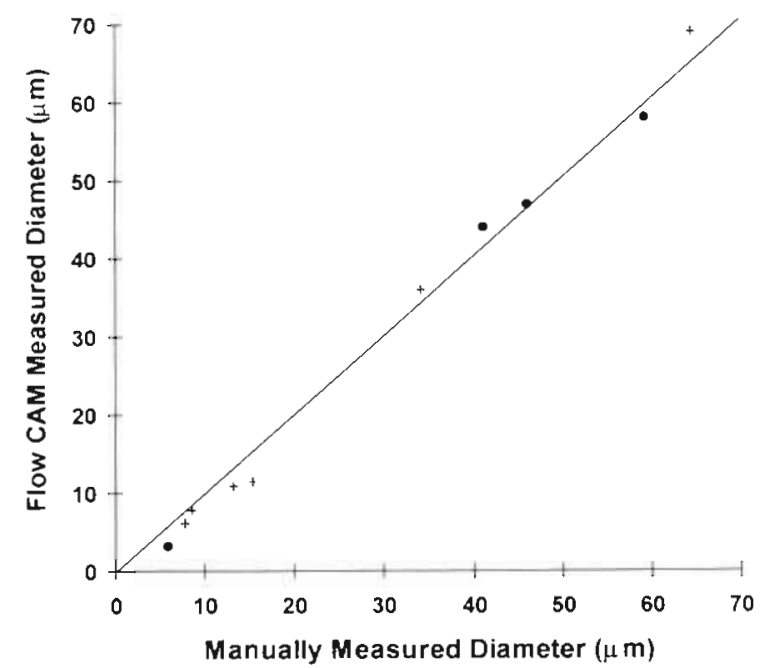

Fig. 6. A comparison of the Flow CAM and manually measured mean particle sizes for different phytoplankton cells (+) and beads $(\bullet)$ ranging from 9 to $70 \mu \mathrm{m}$ in diameter. Solid line shows the $1: 1$ line $\left(r^{2}>0.996\right)$

\section{Size distributions}

The size distributions for 6 phytoplankton cultures are shown in Fig. 8. Alexandrium tamarense shows a prominent peak at the average size of $36 \mu \mathrm{m}$ and the presence of smaller cells and theca in a pronounced tail left of the main peak. In contrast, the distribution of Biddulphia sp. has a very sharp peak at the single cell size of $10 \mu \mathrm{m}$ with a tail to the right of this peak, due to the different chain lengths present. Cyclotella menveghiniana has a somewhat broad peak around $10 \mu \mathrm{m}$. Gambierdiscus toxicus has a distribution quite different from the others due to its larger size. The Nitzschia ovalis and Navicula sp. curves show the presence of extremely small particles. Little size variation is present in these last 2 since these cells are near the $3 \mu \mathrm{m}$ optical resolution of the Flow CAM system and neither cell type forms chains.

\section{Natural assemblages}

The size distributions of natural particle populations from various water types are displayed in Fig. 9. Particles from the tropical water sample (Fig. 9A) were skewed towards smaller particles with few large particles present. The Boothbay Harbor particles during early January (Fig. 9B) are dominated by small particles as well. In
Table 1 Flow CAM size measurements of bead standards

\begin{tabular}{|lcccr|}
\hline $\begin{array}{l}\text { Nominal } \\
\text { bead size } \\
(\mu \mathrm{m})\end{array}$ & $\begin{array}{c}\text { Average } \\
\text { measured size } \\
(\mu \mathrm{m})\end{array}$ & & $\begin{array}{c}\text { \%tandard } \\
\text { deviation } \\
(\mu \mathrm{m})\end{array}$ & $\% \mathrm{cv}$ \\
\hline 15 & 17.09 & 13.9 & 2.56 & 17.1 \\
30 & 30.51 & 1.7 & 3.22 & 10.7 \\
41 & 41.69 & 1.68 & 3.47 & 8.5 \\
61 & 61.2 & 0.3 & 2.47 & 4.0 \\
\hline
\end{tabular}

February (Fig. 9C), the Boothbay Harbor size spectra is significantly different due to a bloom of chains of the 30 to $40 \mu \mathrm{m}$ diatom of the genus Thalassiosira. Particles larger than $40 \mu \mathrm{m}$ were dominated by chains of various lengths. The March distribution (Fig. 9D) shows another significantly different shape due to the abundance of an oligotrich ciliate, 70 to $90 \mu \mathrm{m}$ in equivalent spherical diameter.

When the Flow CAM was used to continually monitor particles during the inbound leg of a research cruise across the Gulf of Maine, regions of larger and smaller cells were observed (Fig. 10). Cell size tended to vary with ocean surface temperature along the transect. Cell abundance was more variable than mean cell size or biomass, especially within the colder Eastern Maine Coastal current waters. Larger cell types present in warmer waters were dominated by the dinoflagellate Ceratium spp. Smaller particies dominating at the end of the transect were observed to be chains of $10 \mu \mathrm{m}$ diatoms. Total biomass peaks (Fig. 10D) reflect the presence of larger cells, more than a higher total abundance (Fig. 10B). Variation in size structure also is controlled primarily by the presence/absence of larger cells.

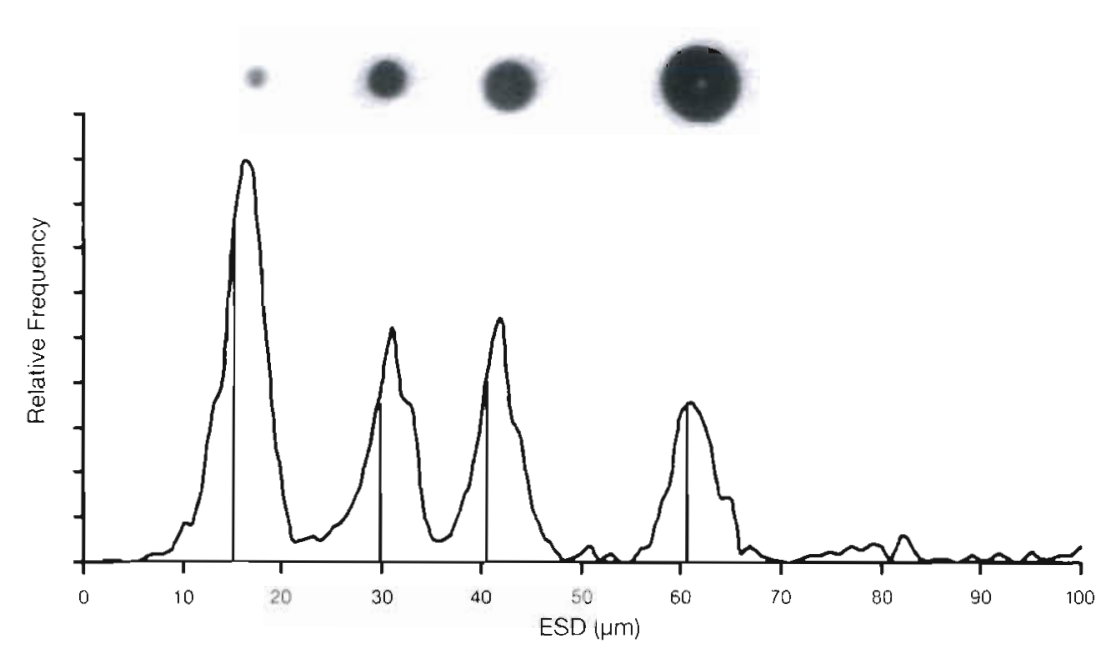

Fig. 7. Size distributions as measured by the Flow CAM for a mixture of 15, 30, 41 and $61 \mu \mathrm{m}$ latex beads. Vertical lines show manufacturer's stated size 


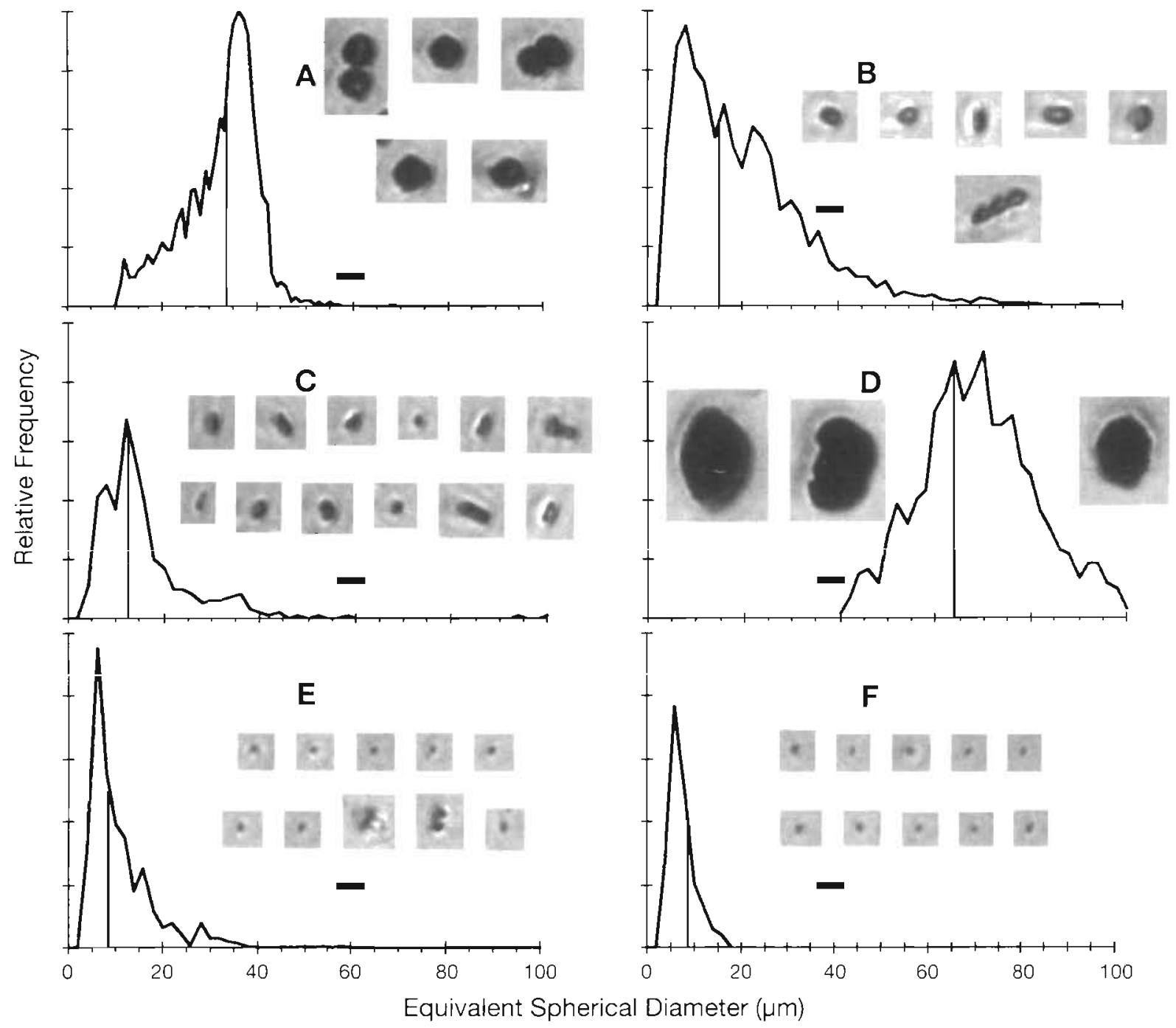

Fig. 8. Size distributions as measured by the Flow CAM for (A) Alexandrium tamarense, (B) Biddulphia sp., (C) Cyclotella meneghiniana, (D) Gambierdiscus toxicus, (E) Nitzschia ovalis and (F) Navicula sp. Vertical lines show average manual sizes.

Size information combined with images of the cells may be used to discriminate different cell populations. Bar $=20 \mu \mathrm{m}$

\section{DISCUSSION}

We have shown that this system can accurately count and size particles and cells in cultures and natural assemblages. It may be used at sea to analyze populations from discrete bottle samples or pumped underway water. In any of these applications, samples may be rapidly processed and the results readily obtained.

\section{Sources of error}

Cells near $3 \mu \mathrm{m}$ (the optical resolution of the system) may be difficult to count if they are either senescent or in chains. When the system is used in auto-trigger mode (no fluorescence measurement), small, empty frustules are indistinguishable from live cells and may introduce counting errors as was the case with the Nitzschia ovalis culture (Fig. 8E). Measurements of such samples may be improved by diluting the cells and imaging in fluorescence-triggered mode which will avoid counting empty frustules. If cells in a chain are closely spaced, the entire chain may be counted as one cell. The user may correct for this by noting the size of single cells in the Flow CAM results spreadsheet and using this information to determine the number of cells in each chain by dividing the chain area by the single cell area to yield cell counts. This is further complicated if, as in the case of Biddulphia sp., single cells are near the 3 pixel size limit and are therefore 
undersized, leading to an overestimate of the number of cells present per chain. This may be corrected by manually measuring single cells at higher magnification and then computing cells per each chain in the spreadsheet.

The current Flow CAM system is configured with a horizontal flow chamber and horizontal tubing to the chamber and a $1 \mathrm{ml} \mathrm{min}^{-1}$. flow rate. If particles in the sample have a rapid sink rate or tend to swim toward the surface of the sample container, they may not reach the counting area of the flow chamber consistently. We encountered this with Ditylum brightwellii (Fig. 5; Expt 5) and Dunaliella cf. tertiolecta (Fig. 5; Expt 2 \& 11-15) which had a slightly larger Flow CAM variation than the manual method, although the problem was not severe. This problem will be alleviated by configuring our next generation instrument with a vertical flow and a faster sample processing

Sinking and sticky cells may also foul the flow chamber and be counted repeatedly. This problem is partially corrected by configuring the system with vertical flow. It is easily corrected by reviewing the data and removing all particles with identical positions in the original image.

Cell clumping also presents a problem. Some of the Chaetoceros neogracile counting errors (Fig 5B) were caused by the tendency of these cells to clump. In some cases, clumping may be substantially reduced by aqitating the specimen aggressively prior to drawing it into the Flow CAM for counting. This particular strain of Chaetoceros has extremely short spines and could tolerate the agitation without further clumping. However, strains with longer spines may become more entangled with stirring. Furthermore, delicate cells and some natural assemblages may not be aggressively stirred without disintegrating

Samples obtained for Flow CAM counts are also subject to sampling errors. If a sample is diluted to reduce the number of cells per field of view, there is the possibility of introducing a dilution error. The user may also introduce a sampling error when extracting a sample of a large culture. This may be reduced by careful agitation prior to sampling.

Finally, sizing errors become significant when particle size approaches 3 pixels $(6.6 \mu \mathrm{m})$. This error cannot be avoided but must be noted in any size related computation. As particles fall below this limit, however, they are still detectable and will be counted. If the user wishes to prevent this error by specifying a minimum particle size, the Flow CAM computer program's 'acceptable particle size' menu may be used.

Compared to traditional microscope methods, the Flow CAM is much more suited to processing natural water samples if some taxonomic information may be sacrificed. This system is also much faster at counting
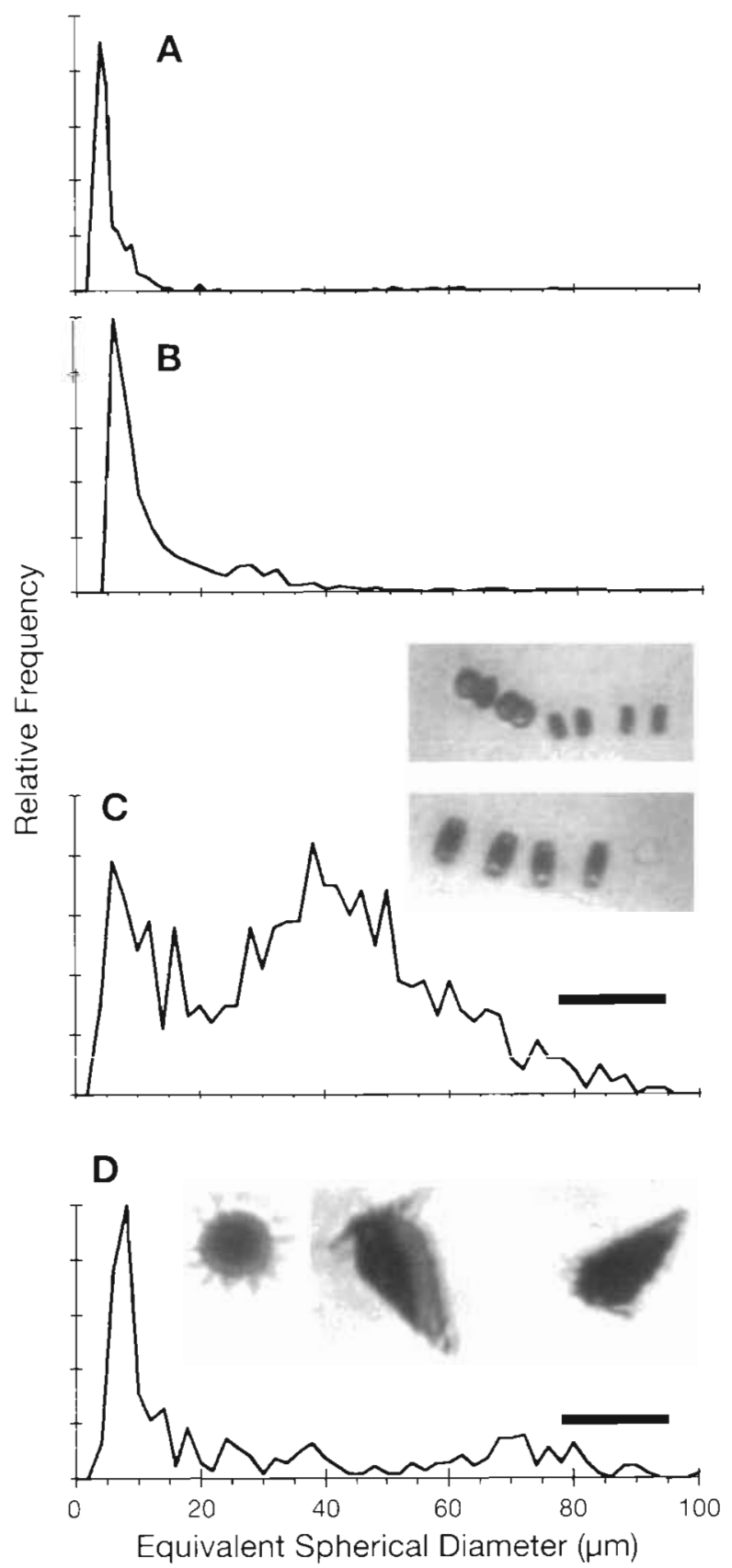

Fig. 9. Flow CAM measured particle size distributions for (A) tropical water (Florida Keys, USA), and for Boothbay Harbor, Maine, USA, during (B) early January, (C) a February bloom of the chain forming diatom Thalassiosira sp. and (D) a March bloom of a 60 to $80 \mu \mathrm{m}$ oligotrich ciliate. Photographs are actual Flow CAM images of the dominant cells. Scale bar $=50 \mu \mathrm{m}$

cells in culture. It requires little specimen preparation other than dilution and allows counting and sizing of unpreserved samples. Furthermore, data is automatically stored in spreadsheets and as digital images, allowing recall of data on each particle. 


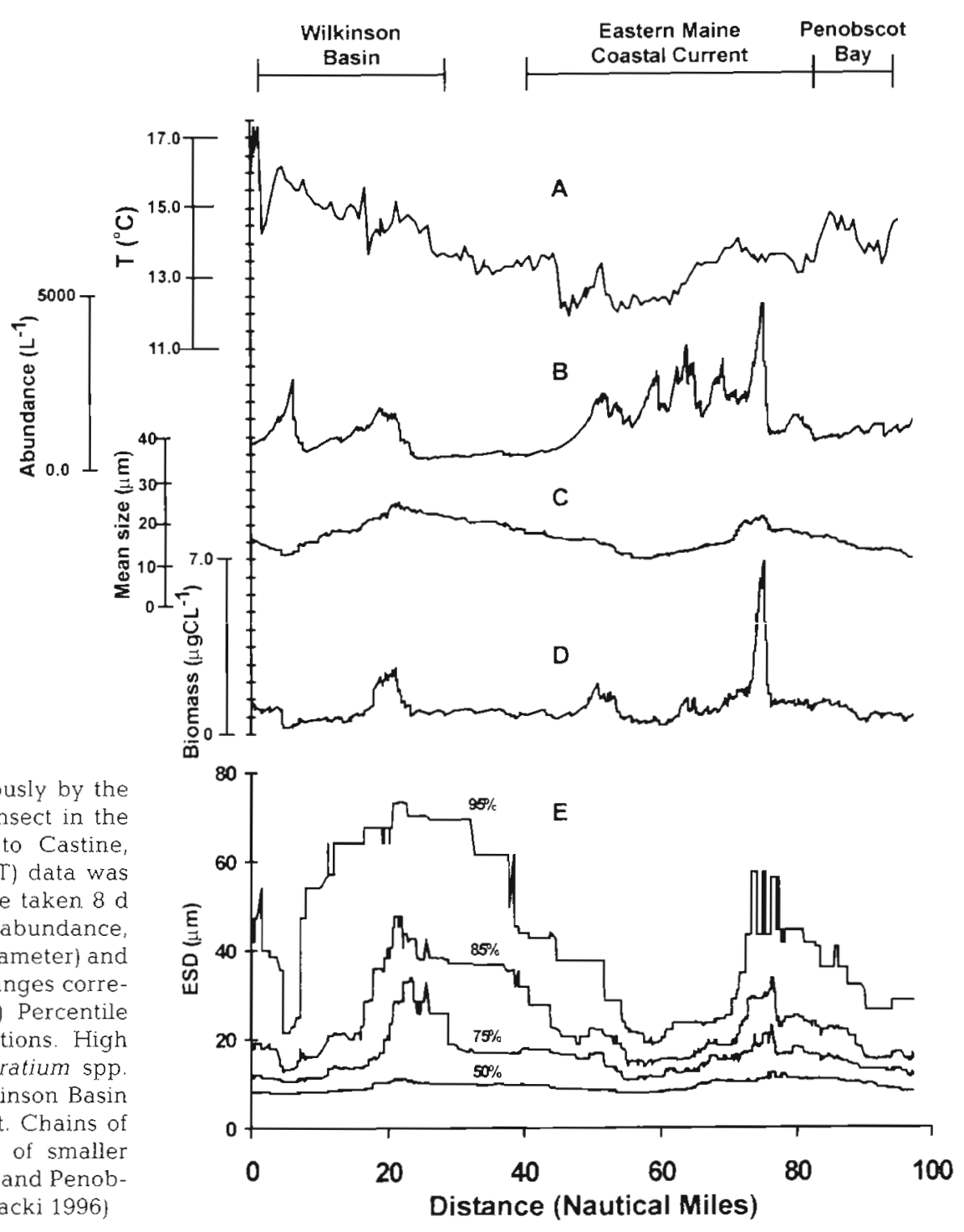

Fig. 10. Particle data measured continuously by the Flow CAM while underway along a transect in the Gulf of Maine from Wilkinson Basin to Castine, Maine. (A) Sea surface temperature (SST) data was extracted from an AVHRR satellite image taken $8 \mathrm{~d}$ after the cruise. (B) Microplankton cell abundance, (C) mean cell size (equivalent spherical diameter) and (D) biomass show patchiness and cell changes corresponding to different water masses. (E) Percentile lines show the population size distributions. High numbers of the large dinoflagellate Ceratium spp. caused the peaks in the cell size in Wilkinson Basin and in the eastern Maine coastal current. Chains of small diatoms predominated in regions of smaller cells in the eastern Maine coastal current and Penobscot Bay. (Redrawn from Sieracki \& Sieracki 1996)

While a count based on the Coulter principle (Coulter 1957) could be conducted more rapidly than a Flow CAM count, no images would be acquired, preventing the use of any identification based on taxonomic features. Also, no particle optical properties could be measured. In the case of a cell culture with little taxonomic or optical diversity, a Coulter Counter would provide an equal amount of useful information. However for the case of diverse cultures or natural assemblages, the Flow CAM would provide more useful information.

The Flow CAM specifications make it more suited to the analysis of larger plankton than a conventional flow cytometer. The maximum flow rate of $1 \mathrm{ml} \mathrm{min}^{-1}$ is much greater than the flow cytometer rate of $100 \mu l$ $\mathrm{min}^{-1}$. The particle size range of 3 to $100 \mu \mathrm{m}$ goes well beyond the flow cytometer particle measurement range of 0.5 to $20 \mu \mathrm{m}$ in conventional instruments such as the Becton Dickinson FACScan. While laser beam size causes significant flow cytometer sizing errors beyond this limit, the Flow CAM accuracy increases with larger size. Since the Flow CAM measures the particle size directly from the image, it will be able to size any particle within the field of view $(1 \times 1 \mathrm{~mm})$. In practice, any cells greater than $500 \mu \mathrm{m}$ may not be adequately sampled. Additionally, the Flow CAM provides images of each detected particle for morphological analysis not possible with conventional flow cytometers.

The Flow CAM flow rate and sizing performance are due largely to the depth of focus enhancing optical element. With it, the imaged particles are acceptably in focus through a $300 \mu \mathrm{m}$ depth of focus, allowing a high flow rate. Without this element, a $300 \mu \mathrm{m}$ depth of focus would only be feasible by decreasing the system numerical aperture by a factor of 2.2 which would 
degrade the resolution to $6.6 \mu \mathrm{m}$ and decrease the light throughput of the system to $20 \%$ of the nominal value, making it difficult to detect particle fluorescence.

\section{Natural assemblages}

In the summer, the Gulf of Maine features a welldeveloped Eastern Maine Coastal current of cooler, fresher, nutrient-rich water moving southwesterly along the coast, with warmer, stratified, nutrient-poor waters over the central Gulf basins (Townsend 1991). Flow CAM analysis along a transect across these waters indicate how plankton community size structure varies with water mass changes. Biomass variations in the 10 to $80 \mu \mathrm{m}$ size range (Fig. 10D) are driven by the combination of changes in cell abundances (Fig. 10B) and the presence of large cells (Fig. 10E). The median cell size (50\% in Fig 10E) shows remarkably little variation across these different water masses. In waters where cells were larger, abundance had a large impact on biomass. Large variations in cell abundances in the coastal current section were dampened in the biomass due to the dominance of small cells. The pattern we observed, with larger cells dominating in the Wilkinson Basin and smaller cells prevalent in the coastal current, was not expected. The Wilkinson Basin water was a summer stratified, nutrient-poor system, where one might expect smaller cells to be dominant. The presence of Ceratium spp. there, while not uncommon, shifted the size spectrum dramatically. The nutrient-rich coastal current waters might have been expected to have larger cells. While diatoms were prevalent, they were smaller than the Ceratium spp. cells, and yielded lower mean cell sizes.

\section{Applications}

The Flow CAM is useful for monitoring underway water and water pumped from depth. Data and images from each detected passing particle can be much more meaningful than bulk measurements such as those taken with conventional flow through fluorometers. While the Flow CAM is not capable of direct in situ measurements (as is the VPR), pumped water from depths of interest can be analyzed using the Flow CAM. Unlike other instruments, the Flow CAM is optimized to analyze microplankton in continuously pumped samples, discrete natural samples and laboratory cultures.

While the results obtained with the Flow CAM illustrate the usefulness of the system in analyzing different specimen types, they also illustrate the limitations and sources of error which must be addressed when using the system. Despite these shortcomings, the accuracy of the Flow CAM and the utility of the interactive scattergram, image capture and cell size data make this automated system attractive for use in many applications where tedious, time consuming traditional methods are presently used. Potential applications include studies of plankton community structure, ocean optics, and monitoring of harmful species of algae or protozod.

The Flow CAM prototype is now available as part of the instrumentation suite at the J. J. Maclsaac Facility for Individual Particle Analysis. The next generation system will be added in the future.

Acknowledgements. We are grateful to Steve Morton and Heather Anne Wright for providing several of the cultures used in this study and for performing the majority of the manual cell counts. We appreciate the help of Justyna Nicinski with specimen preparation and improvement of the user interface. The authors thank Eric W. Hansen and Christopher $G$. Levey for their valuable consultation and for the fabrication of the binary optical elements. We are grateful to the captain and crew of the RV 'Argo Maine' for assistance with ship systems. The depth of focus enhancing optical element development was mostly supported by National Institutes of Health grant RO1-GM36594. Development of the remainder of the original. Flow CAM system was supported by Office of Naval Research grants number N000-14-94-1-0972 and N00014-951-0460. Development of a higher performance Flow CAM is funded under NSF grant OCE 97-11168.

\section{LITERATURE CITED}

Chisholm SW, Armbrust EV, Olson RJ (1986) The individual cell in phytoplankton ecology: cell cycles and applications of flow cytometry. In: Platt T, Li WKW (eds) Photosynthetic picoplankton. Can Bull Fish Aquat Sci 214:343-369

Coulter WH (1957) High speed automatic blood cell counter and cell size analyzer Proc Natl Electronic Conf 12 $1034-1042$

Davis C, Gallager S, Solow A (1992) Microaggregations of oceanic plankton observed by towed video microscopy. Science 257:230-232

Dubelaar GBJ, Groenwegen AC, Stokdijk W, van den Engh GJ, Visser JWM (1989) Optical plankton analyser a flow cytometer for plankton analysis, II: specifications. Cytometry 10:529-539

Dubelaar GBJ, Jonker RR, Meulemans JTM, van Veen JJF (1994) Phytoplankton analysis by (EurOPA) flow cytometry: current and future applications in environmental control. Proc Oceans 94 and Osates 94 IEEE Cat $\mathrm{Nr}$ 94CH3472-8, Inst Electrical and Electronics Engineers, New York, p 583-687

Freimann R (1996) In situ measurement of zooplankton volume-frequency distribution by means of light scattering. Cont Shelf Res 16:421-434

Gallager SM, Davis CS, Epstein AW, Solow A, Beardsley RC (1996) High-resolution observations of plankton spatial distributions correlated with hydrography in the Great South Channel, Georges Bank. Deep Sea Res II 43: $1627-1663$

Hüller R, Glossner E, Shaub S, Weingärtner J, Kachel V (1994) The macro flow planktometer - a new device for 
volume and fluorescence analysis of macro plankton including triggered video maging in flow. Cytometry 17 : $109-118$

Kachel V, Benker G, Lichtnau K, Valet G, Glossner E (1979) Fast imaging in flow: a means of combining flow-cytometry and image analysis. J Histochem Cytochem 27: $335-341$

Kay DB, Cambier JL, Wheeless LL Jr (1979) lmaging in flow. J Histochem Cytochem 27:329-334

Maddux WS, Kanwisher JW (1965) An in situ particle counter Limnol Oceanogr 10 (suppl):R162-R168

McCave IN (1984) Size spectra and aggregation of suspended particles in the deep ocean. Deep Sea Res 31:329-352

Olson RJ, Zettler ER, Chisholm SW, Dusenberry JA (1991) Advances in oceanography through flow cytometry. Particle analysis in oceanography. NATO ASI Series, G27, Springer-Verlag, Berlin, p 392-399

Peeters JCH, Dubelaar GBJ, Ringelberg J, Visser JWM (1989) Optical plankton analyser: a flow cytometer for plankton analysis. Cytometry 10:522-528

Phinney DA, Cucci TL (1989) Flow cytometry and phytoplankton. Cytometry 10:511-521

Sheldon RW, Prakash A, Sutcliff WH Ji (1972) The size distribution of particles in the ocean. Limnol Oceanogr 17 $327-340$

Sieburth JM, Smetacek V, Lenz J (1978) Pelagic ecosystem structure: heterotrophic compartments of the plankton and their relationship to plankton size fractions. Limnol Oceanogr 23:1256-1263

Editorial responsibility: Otto Kinne (Editor), Oldendorf/Luhe, Germany
Sieracki CK (1995) An experimental and computational study of binary optical elements for aberration correction in three dimensional fluorescence microscopy. PhD dissertation, Dartmouth College, Hanover, NH

Sieracki CK, Sieracki ME (1996) A high throughput volume particle in-flow maging system. Proc Ocean Optics XIII SPIE 2963.886-891

Tounsend DW (1991) Influences of oceanographic processes on the biological productivity of the Gulf of Maine. In: Anderson RS, Kennish MJ, Stickney RR (eds) Reviews in aquatic sciences. CRC Press, Inc, Boca Raton, p 211-230

Venrick EL (1978) How many cells to count? In: Sournia A (ed) Phytoplankton manual. UNESCO, Paris, p 167-180

Wietzorrek J, Stadler M, Kachel V (1994) Flow cytometric imaging - a novel tool for identification of marine organisms. Proc Oceans 94 and Osates 94 IEEE Cat $\mathrm{Nr}$ 94CH3472-8, Inst Electrical and Electronics Engineers, New York, p 688-693

Yentsch CM, Horan PK, Dortch Q. Haugen E, Legendre L, Murphy LS, Perry MJ, Phinney DA, Pomponi SA, Spinrad RW, Wood M, Yentsch CS, Zahuranec BJ (1983) Flow cytometry and cell sorting: a technique for analysis and sorting of aquatic particles. Limnol Oceanogr 28: $1275-1280$

Yentsch CM, Spinrad RW (1987) Particles in flow. Mar Technol Soc J 21:58-67

Yentsch CM, Yentsch CS (1984) Emergence of optical instrumentation for measuring biological properties. Oceanogr Mar Biol Annu Rev 22:55-98

Submitted: October 21, 1997; Accepted: May 3, 1998 Proofs received from author(s): June 29, 1998 